\title{
Instruments for the Assessment of Behavioral and Psychosocial Functioning in Duchenne and Becker Muscular Dystrophy; a Systematic Review of the Literature
}

Citation for published version (APA):

Hellebrekers, D. M. J., Lionarons, J. M., Faber, C. G., Klinkenberg, S., Vles, J. S. H., \& Hendriksen, J. G. M. (2019). Instruments for the Assessment of Behavioral and Psychosocial Functioning in Duchenne and Becker Muscular Dystrophy; a Systematic Review of the Literature. Journal of Pediatric Psychology, 44(10), 1205-1223. https://doi.org/10.1093/jpepsy/jsz062

Document status and date:

Published: 01/01/2019

DOI:

10.1093/jpepsy/jsz062

Document Version:

Publisher's PDF, also known as Version of record

Document license:

Taverne

Please check the document version of this publication:

- A submitted manuscript is the version of the article upon submission and before peer-review. There can be important differences between the submitted version and the official published version of record. People interested in the research are advised to contact the author for the final version of the publication, or visit the DOI to the publisher's website.

- The final author version and the galley proof are versions of the publication after peer review.

- The final published version features the final layout of the paper including the volume, issue and page numbers.

Link to publication

\footnotetext{
General rights rights.

- You may freely distribute the URL identifying the publication in the public portal. please follow below link for the End User Agreement:

www.umlib.nl/taverne-license

Take down policy

If you believe that this document breaches copyright please contact us at:

repository@maastrichtuniversity.nl

providing details and we will investigate your claim.
}

Copyright and moral rights for the publications made accessible in the public portal are retained by the authors and/or other copyright owners and it is a condition of accessing publications that users recognise and abide by the legal requirements associated with these

- Users may download and print one copy of any publication from the public portal for the purpose of private study or research.

- You may not further distribute the material or use it for any profit-making activity or commercial gain

If the publication is distributed under the terms of Article 25fa of the Dutch Copyright Act, indicated by the "Taverne" license above, 


\title{
Instruments for the Assessment of Behavioral and Psychosocial Functioning in Duchenne and Becker Muscular Dystrophy; a Systematic Review of the Literature
}

\author{
Danique M. J. Hellebrekers, ${ }^{1,2}$ MSc, Judith M. Lionarons, ${ }^{1,2}$ MD, \\ Catharina G. Faber, ${ }^{2,3}$ MD, PHD, Sylvia Klinkenberg, ${ }^{1,2,3}$ MD, PHD, \\ Johan S. H. Vles, ${ }^{2}$ MD, PHD, and Jos G. M. Hendriksen, ${ }^{1,2,4} \mathrm{PHD}_{\mathrm{H}}$ \\ ${ }^{1}$ Kempenhaeghe Centre for Neurological Learning Disabilities, Heeze, The Netherlands, ${ }^{2}$ Maastricht University, \\ School for Mental Health and Neuroscience, Maastricht, The Netherlands, ${ }^{3}$ Maastricht University Medical Centre, \\ Department of Neurology, Maastricht, The Netherlands and ${ }^{4}$ Duchenne Centre Netherlands
}

All correspondence concerning this article should be addressed to D. M. J. Hellebrekers, Centre for Neurological Learning Disabilities, Sterkselseweg 65, 5591 VE, Heeze, The Netherlands. E-mail: hendriksenj@kempenhaeghe.nl

Received February 13, 2019; revisions received July 3, 2019; accepted July 5, 2019

\begin{abstract}
Objective This systematic review aims to provide an overview of instruments used to assess behavioral and psychosocial functioning of patients with Duchenne and Becker muscular dystrophy, as well as to review the psychometric properties and applicability of these instruments. Methods Five databases (Embase, Psyc.info, ERIC, Pubmed/Medline, and Cochrane) were searched from inception to June, 2018. Potential articles were rated by two independent reviewers. A predefined PROSPERO form (CRD42017074518) was used to extract data from included articles. Results Sixty-one instruments were used in 54 studies. The Child Behavior Checklist is commonly used, but it lacks disease specific psychometric information. Sixteen instruments that contained disease specific psychometric information were included for final evaluation. The results displayed three instruments that are potentially valid for screening of psychosocial problems: The Psychosocial Adjustment and Role Skills Scale 3rd edition, the Pediatric Quality of Life Inventory Generic module, and the Life Satisfaction Index for Adolescents with Duchenne muscular dystrophy. Appropriate instruments for screening of behavioral problems may be: the Strengths and Difficulties Questionnaire, the Generalized Anxiety Disorder-7 item questionnaire, and the Patient Health Questionnaire-9 item questionnaire. Conclusions Further research on psychometric properties of screening instruments is crucial to ascertain a gold standard for clinical and research purposes. Meanwhile, for definite diagnostics purposes we recommend a multimethod, multisource, multisetting assessment in this high-risk population.
\end{abstract}

Key words: systematic review; muscular dystrophy; Duchenne-Becker; instruments; screening; diagnostics; behavior; psychosocial; psychometrics.

\section{Introduction}

Duchenne muscular dystrophy (DMD) and Becker muscular dystrophy (BMD) are allelic disorders covering the spectrum of X-linked dystrophinopathies, and are further mentioned as the dystrophinopathy population. Both disorders are caused by mutations in the $D M D$ gene, that encodes multiple dystrophin isoforms in various tissues (i.e., muscles and the brain) 
(Doorenweerd et al., 2017; Hendriksen et al., 2015; Muntoni, Torelli, \& Ferlini, 2003). Depending on mutation location one or more dystrophin protein isoforms are absent in $\mathrm{DMD}$, resulting in progressive muscle wasting (Hendriksen et al., 2015; Muntoni et al., 2003). By contrast, in BMD, gene mutations cause an open reading frame with a milder and more variable phenotype (Mori-Yoshimura et al., 2018). In addition to the myopathy, behavioral disorders are common in the dystrophinopathy population (Hendriksen \& Vles, 2008; Snow, Anderson, \& Jakobson, 2013; Young et al., 2008,). High prevalence rates of autism spectrum disorders (ASD; up to $21 \%$ ), attention-deficit hyperactivity disorders (ADHD; up to $32 \%$ ), anxiety and depression (up to $27 \%$ ), oppositional defiant disorders $(15 \%)$, and obsessive compulsive disorders (up to $5 \%$ ) have been described in DMD compared to the general population (Banihani et al., 2015; Hendriksen \& Vles, 2008; Hinton et al., 2009; Pane et al., 2012; Ricotti et al., 2016; Steele et al., 2008). Additionaly, impaired psychosocial fuctioning has been reported in DMD (Thompson, Zeman, Fanurik, \& Sirotkin-Roses, 1992; Uzark et al., 2012). Three previous BMD studies also investigated the presence of behavioral disorders, (Melo et al., 1995; Mori-Yoshimura et al., 2018; Young et al., 2008) but only one study found increased prevalence rates of attention problems (33\%), ASD (8.3\%), social problems $(33 \%)$, and withdrawn behavior $(33 \%)$ in BMD compared to the general population (Young et al., 2008). Current evidence suggests that these behavioral disorders are partially caused by neurobiological processes and relates them to impaired or altered expression of brain dystrophin isoforms. A relation between the absence of brain dystrophin isoforms and behavioral comorbidities such as ADHD and ASD has been described in patients with DMD (Banihani et al., 2015; Doorenweerd et al., 2017; Pane et al., 2012; Ricotti et al., 2016). There is no research available yet on possible relations between partially functional dystrophin production in the brain and behavioral comorbidities in BMD. Research on dystrophin-associated behavioral comorbidities remains limited for both disorders and no clear explanation exists for the different rates in comorbidities between DMD and BMD. It is suggested that the discrepancy might be explained by the difference in expression of brain dystrophin isoforms in DMD versus $\mathrm{BMD}$, but this needs further investigation.

With the increased life expectancy nowadays due to changes in medical care (i.e., improved ventilation assistence), the dystrophinopathy population is confronted with long-lasting or new mental health issues that negatively influence their quality of life (Birnkrant et al., 2018). Recent standards of care for DMD emphasize that adequate and routine behavioral and psychosocial assessment is crucial (Birnkrant et al., 2018), though current literature lacks an overview of available and adequate instruments. Nonetheless, the updated standards of care for DMD recommend four instruments: The Strenghts and Difficulties Questionnaire (SDQ), the Patient Health Questionnaire (PHQ-9), the Generalized Anxiety disorder 7-item scale (GAD-7), and the Personal Adjustment and Role Skills Scale-III (PARS-III) (Birnkrant et al., 2018). However, disease-specific psychometric information is unknown for the SDQ, the PHQ-9, the GAD-7, and the suitability of the PARS-III for DMD care has been proven by only one previous study (Hendriksen et al., 2009).

Recently, improvements in screening and diagnostics of behavioral and psychosocial problems have received more attention in this high-risk aging population. Several studies have tried to improve the assessment of behavioral and psychosocial problems by using (1) the Diagnostic and Statistical Manual of Mental Disorders (DSM: Banihani et al., 2015), (2) more than one instrument, (e.g., informant-ratings in addition to structured clinical interviews; Banihani et al., 2015; Colombo et al., 2017; Ricotti et al., 2016), or (3) instruments with items relevant to dystrophinopathy (e.g., Muscular Dystrophy Child Health Index of Life with Disabilities questionnaire [MDCHILD] for children with DMD; Propp et al., 2018). However, most studies have used instruments with poor or unevaluated psychometric properties or instruments that contain items unsuited for patients with motor impairments. Therefore, the present systematic review aims to provide an overview of instruments used to assess behavioral and psychosocial functioning, and evaluates their psychometric properties and applicability for the dystrophinopathy population.

\section{Methods}

\section{Search Strategy and Selection Criteria}

This systematic review was conducted according to the Preferred Reporting Items for Systematic Reviews and Meta-Analyses statement (Liberati et al., 2009) and predefined PROSPERO protocol (CRD42017074518). Databases (EMBASE, Psyc.info, ERIC, PUBMED/ Medline, and Cochrane) were searched from inception to July 2017 and updated to June 19, 2018. The search strategy is presented in Supplementary Table 1. To be eligible for inclusion, studies had to (a) include males with dystrophinopathy (i.e., DMD or BMD), (b) examine the psychometric properties of behavioral and psychosocial instruments, (c) be available in English, Dutch, or German, and (4) be longitudinal or crosssectional design studies. Case report studies $(n<10)$, nonpeer reviewed articles, abstracts from scientific 
meetings, intervention studies or studies using an instrument that consisted of one subscale or one item of a questionnaire were excluded.

Two reviewers (D. H.: psychologist and J.L.: Doctor of Medicine, both having clinical experience with patients with DMD and BMD) independently screened titles and abstracts manually for potential inclusion, using the search terms of Supplementary Table 1. Fulltexts of articles were retrieved when inclusion could not be based on title and abstract. Cohen's kappa was used to measure the inter-rater reliability between the two independent reviewers (D.H. and J.L.). If no consensus was reached between the two reviewers, a third independent reviewer (J.H. psychologist with clinical experience in DMD and BMD) examined whether the article fulfilled the inclusion criteria. After selection based on title and abstract, one reviewer (D.H.) screened the full-text of the selected articles to assess whether the article could be included for final evaluation (i.e., data extraction). Doubtful articles were examined by a second independent reviewer (J.H.). Furthermore, reference lists of the selected full-text articles were screened to identify whether additional articles had to be included for review.

\section{Data Collection and Extraction}

One reviewer (D.H.) extracted data from included articles for final evaluation using a predefined form (PROSPERO: CRD42017074518). The following data were extracted: (1) authors and year of publication, (2) demographic characteristics (e.g., age), (3) inand exclusion criteria if specified, (4) study design, (5) instruments used to assess behavioral or psychosocial functioning, (6) results of psychometric properties and applicability of instruments, and (7) study limitations and main conclusion.

\section{Classification of Method of Assessment}

Selected articles were classified according to methods of assessment (Table 2): clinical observation ratings, (semi) structured clinical interviews, informant-ratings, and self-ratings. During clinical observations, a clinician rates the extent of behavioral or psychosocial problems based on clinical judgement. Structured clinical interview instruments are designed to acquire both quantitative as well as qualitative information about the degree of behavioral or psychosocial functioning and are also completed by clinicians. Informant-rating instruments are questionnaires completed by a person who knows the patient well, for instance parents or caregivers. Selfrating instruments are completed by patients themselves.

\section{Evaluation of Psychometric Properties and Applicability}

The psychometric properties of the instruments were evaluated by D.H. using seven criteria (see Table I) from previous (systematic review) studies ( $\mathrm{Hu} \&$ Bentler, 1999; Smeets, Ponds, Verhey, \& van Heugten, 2012; Terwee et al., 2007; Visser-Meily, Post, Riphagen, \& Lindeman, 2004). The applicability of the instruments were evaluated based on versions used in previous studies. The following aspects were assessed: availability (an easily obtained instrument), duration of assessment, and availability in different languages.

\section{Results}

The literature search identified 1,009 articles based on the inclusion criteria. All articles were accessible. After removing duplicates and excluding articles based on title or abstract, a total of 114 articles remained for full-text screening (see Figure 1). Cohen's kappa was calculated to determine the level of agreement between the two independent reviewers (D.H. and J.L.) on title and abstract screening. A moderate agreement was found between the two reviewers, $k=0.72$. After full-text evaluation of the remaining 114 articles, a total of 53 articles were included for final evaluation. Reasons for exclusion were (1) conference abstracts, (2) no assessment of behavioral or psychosocial instruments, (3) small sample size $<10$, (4) study population other than DMD and BMD, or no separate results available for DMD and BMD subpopulation, (5) no crosssectional or longitudinal study design, and (6) language other than English, Dutch, or German. One additional article was extracted from the reference list of the 114 selected articles. This additional article fulfilled the eligibility criteria and was added to the 53 previous included articles, which resulted in a total of 54 included articles (see Figure 1).

\section{Overview of Included Studies and Instruments}

Among the 54 included articles $(N=51 \mathrm{DMD}$ and $N=3$ BMD), 61 different instruments $(n=1$ clinical observation, $n=12$ semistructured interviews, $n=22$ informant-ratings, and $n=26$ self-ratings) were used to assess behavioral and psychosocial functioning (see Table II).

The psychometric properties of these instruments were not evaluated in $33(N=30 \mathrm{DMD}$ and $N=3$ $\mathrm{BMD}$ ) of the 54 articles and were excluded for final evaluation of psychometric properties (see Table III for excluded instruments). Due to the final selection, a total of 21 articles (all DMD) with 16 instruments ( $n=5$ informant-ratings, $n=6$ self-ratings, and $n=5$ instruments with informant-ratings and self-ratings) were reviewed. Patients $(N=2,580)$ included in these $N=21$ studies were aged between 0.7 months and 44 years. 
Table I. Criteria used to Evaluate Psychometric Properties

\begin{tabular}{|c|c|c|c|}
\hline & Insufficient & Moderate & Sufficient \\
\hline 1. Internal consistency ${ }^{\mathrm{a}, \mathrm{b}, \mathrm{d}}$ Cronbach's alpha & $<0.70$ & $0.70-0.80$ & $>0.80$ \\
\hline 2. Test-retest reliability ${ }^{\mathrm{a}, \mathrm{b}}$ Spearman/Pearson correlation & $<0.70$ & $0.70-0.80$ & $>0.80$ \\
\hline $\begin{array}{l}\text { 3. Interrater reliability }{ }^{\text {a,b,d }} \text { Intra-class correlations (ICC), } \\
\text { Pearson correlation or Kappa between raters }\end{array}$ & $<0.70$ & $0.70-0.80$ & $>0.80$ \\
\hline $\begin{array}{l}\text { 4. Convergent validity }{ }^{\mathrm{a}, \mathrm{b}} \text { Spearman/Pearson correlation } \\
\text { 5. Construct validity }{ }^{\mathrm{a}, \mathrm{b}}\end{array}$ & $<0.30$ & $0.30-0.60$ & $>0.60$ \\
\hline $\begin{array}{l}\text { Principal component analysis } \\
\text { Comparative fit index if available } \\
\text { Standardized root mean square residual }\end{array}$ & Not confirms structure & & $\begin{array}{l}\text { Confirms structure } \\
>0.95 \\
<0.9\end{array}$ \\
\hline 6. Responsiveness $\mathrm{s}^{\mathrm{a}, \mathrm{b}, \mathrm{d}}$ & $\begin{array}{l}\text { Nonsignificant changes: } \\
\quad p>.05 \text {, or effect size }<0.40\end{array}$ & & $\begin{array}{l}\text { Significant changes: } \\
p<.05 \text {, or effect } \\
\text { size }>0.40\end{array}$ \\
\hline \multicolumn{4}{|l|}{ 7. Content validity ${ }^{\mathrm{d}}$} \\
\hline Aim of instrument is clarified & No & & Yes \\
\hline Focus on dystrophinopathy & No & & Yes \\
\hline Clarification of concepts of subscales & No & & Yes \\
\hline Important items for population & No & & Yes \\
\hline $\begin{array}{l}\text { Interpretability of items (simple, no jargon } \\
\text { or two questions at one time) }\end{array}$ & No & & Yes \\
\hline
\end{tabular}

${ }^{\mathrm{a}}$ Visser-Meily et al. (2004).

${ }^{b}$ Smeets et al. (2012).

${ }^{c} \mathrm{Hu}$ and Bentler (1999).

${ }^{\mathrm{d}}$ Terwee et al. (2007).
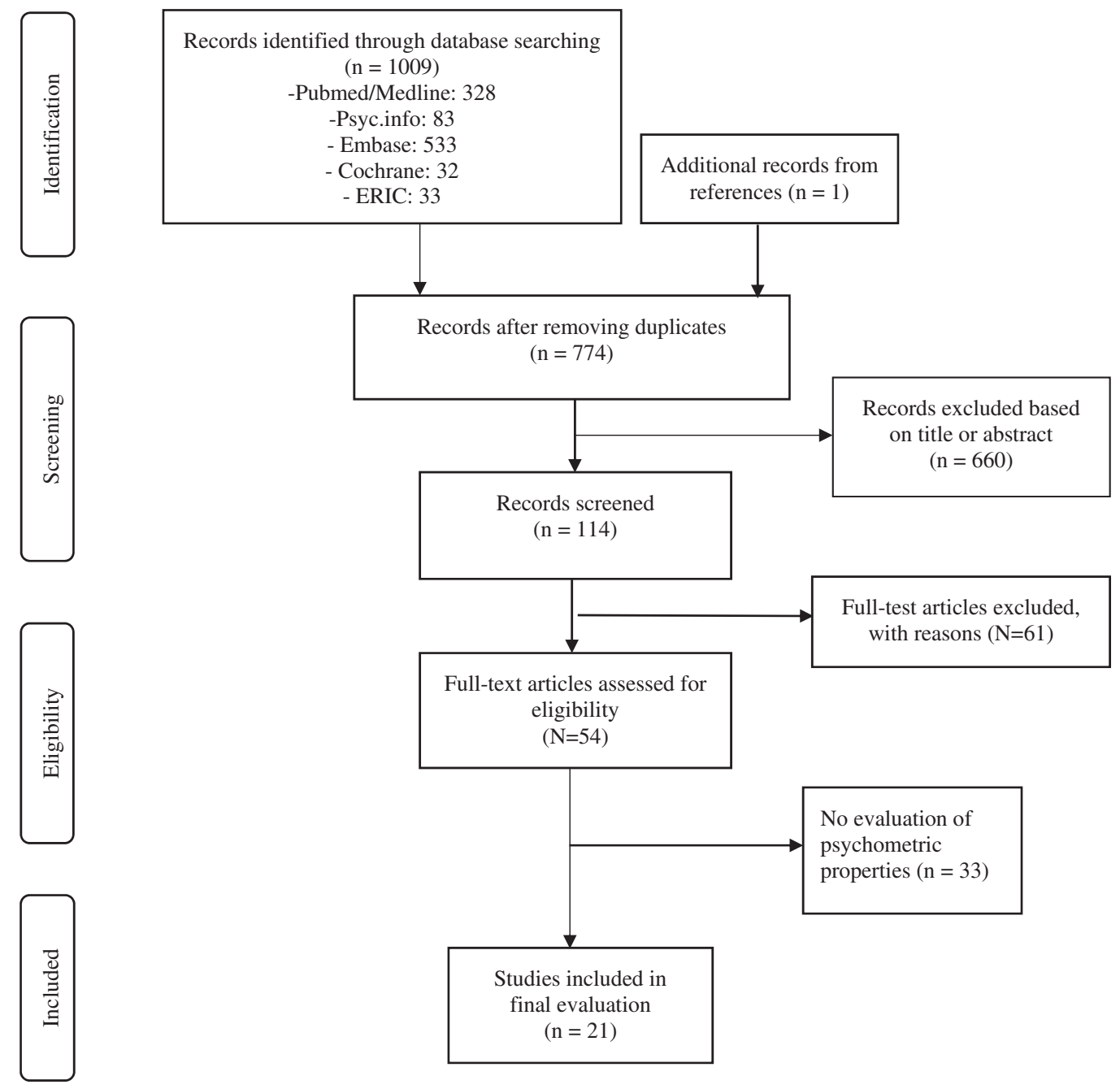

Figure 1. Flowchart of the selected articles. 


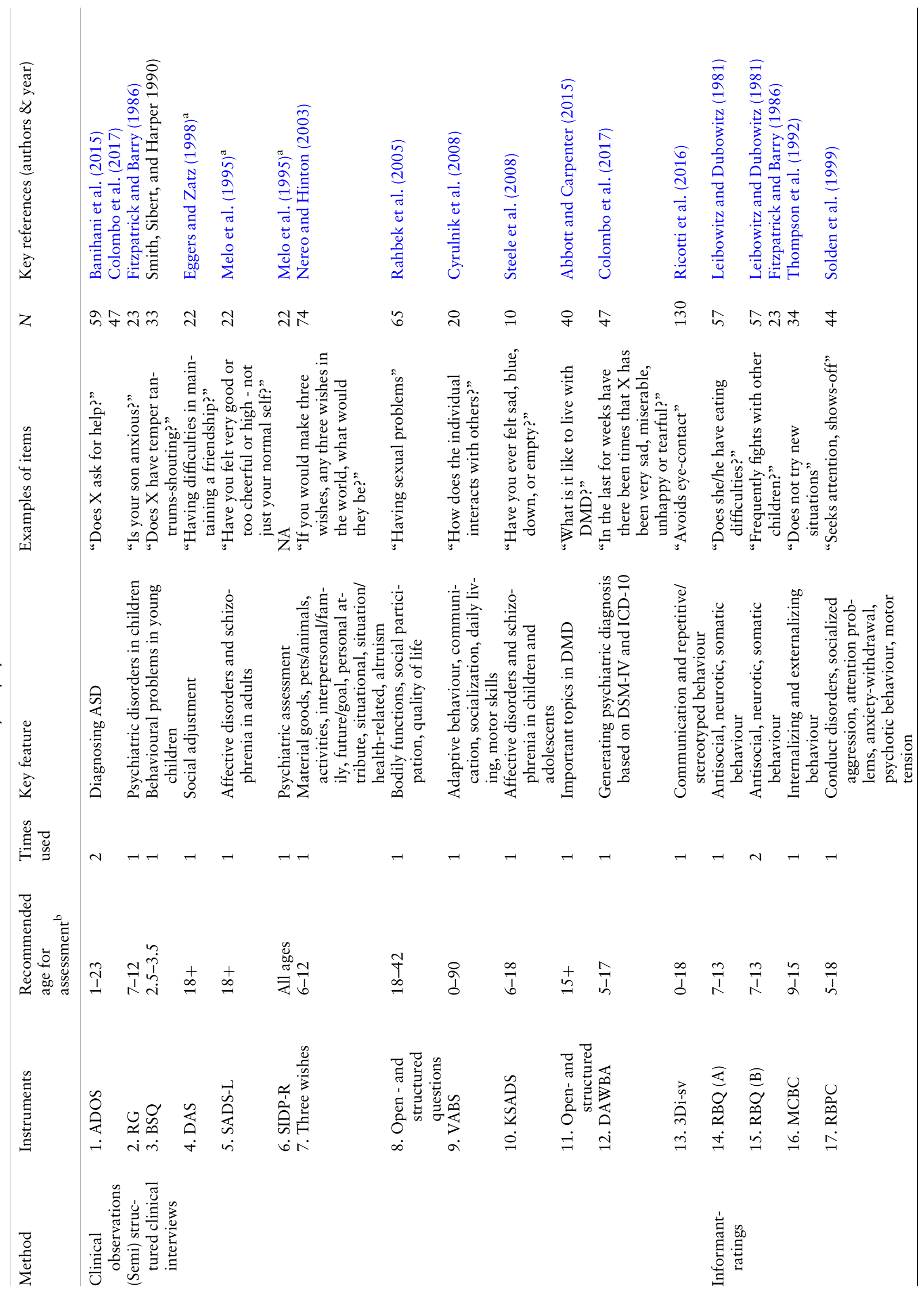




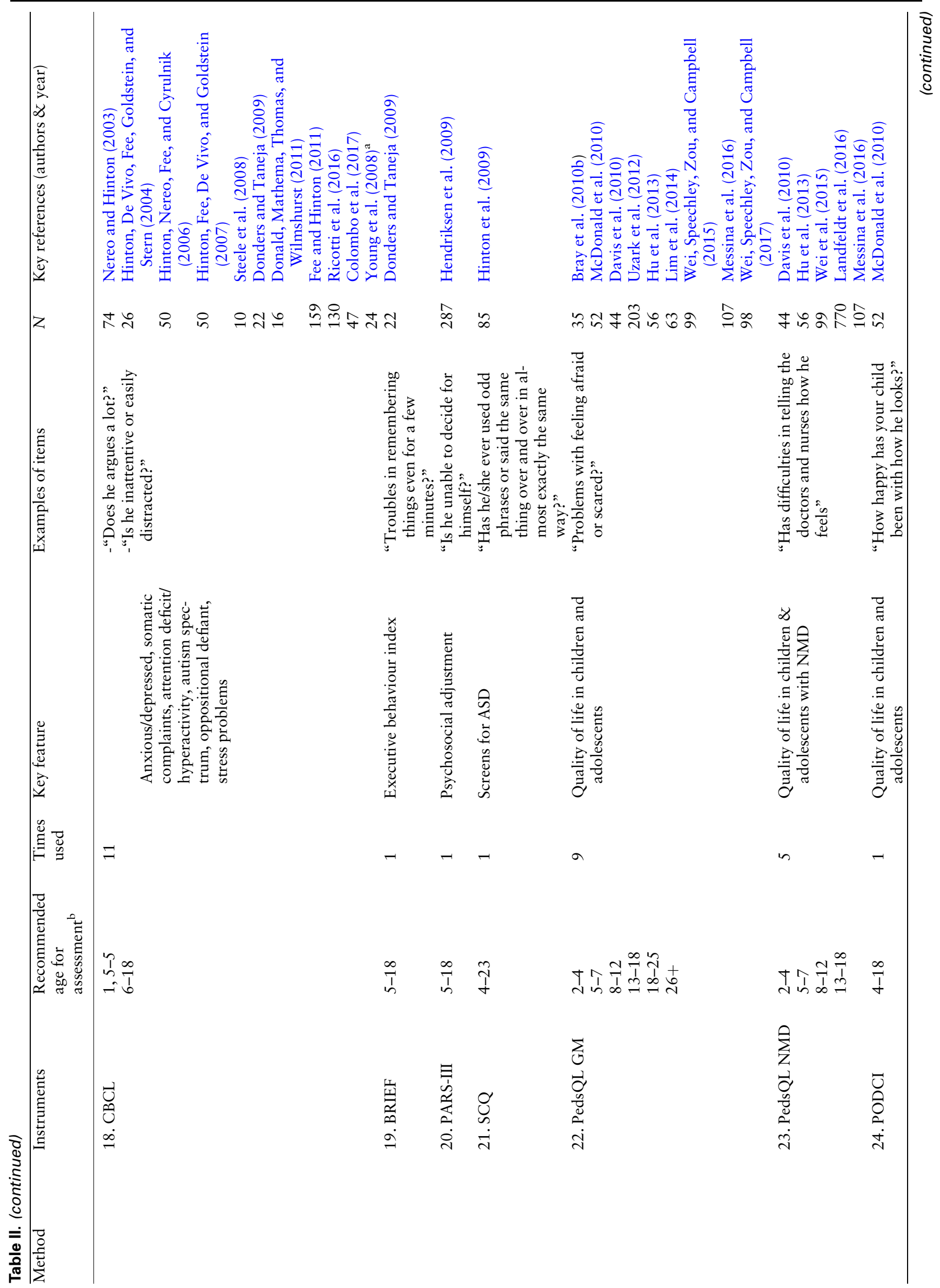




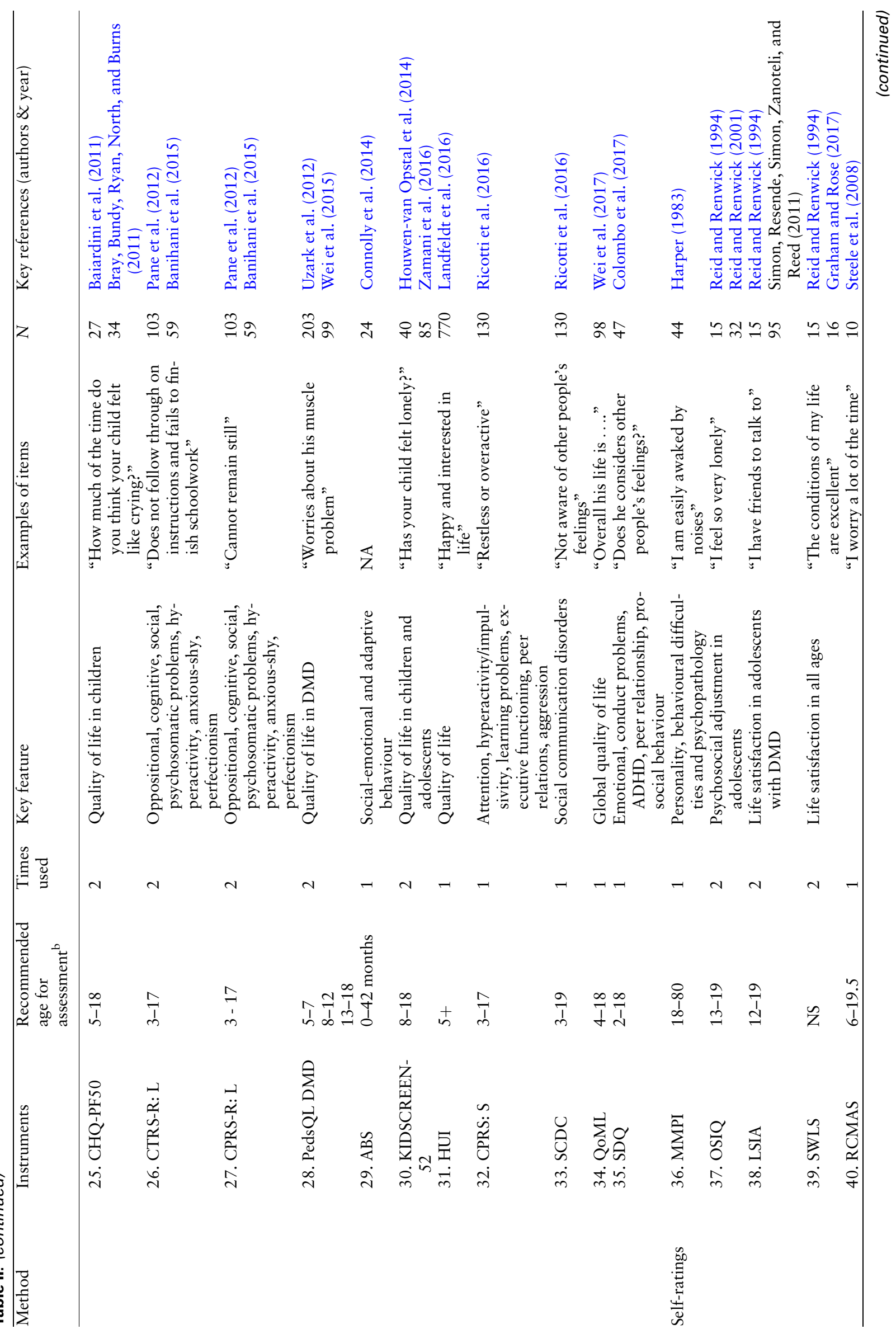




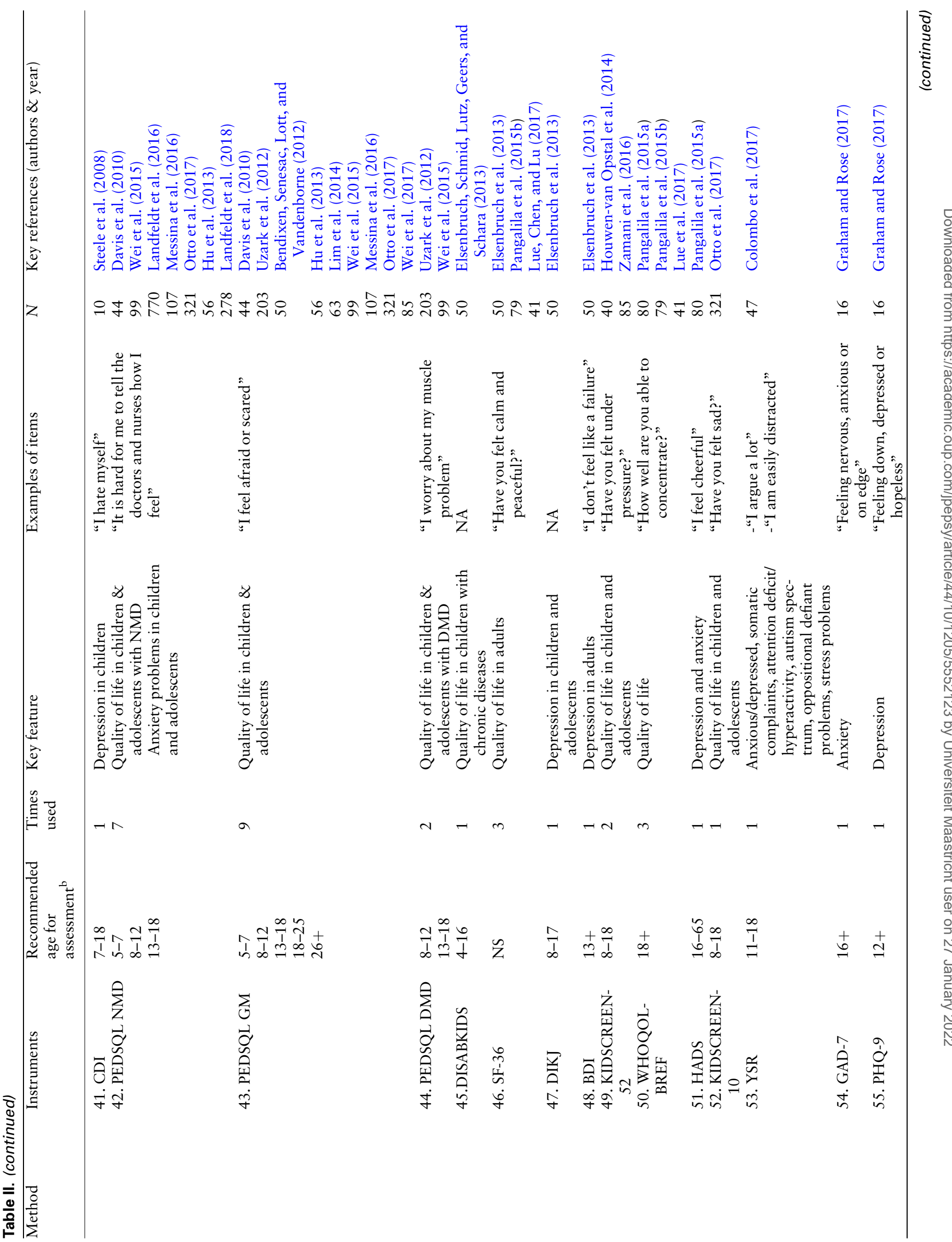




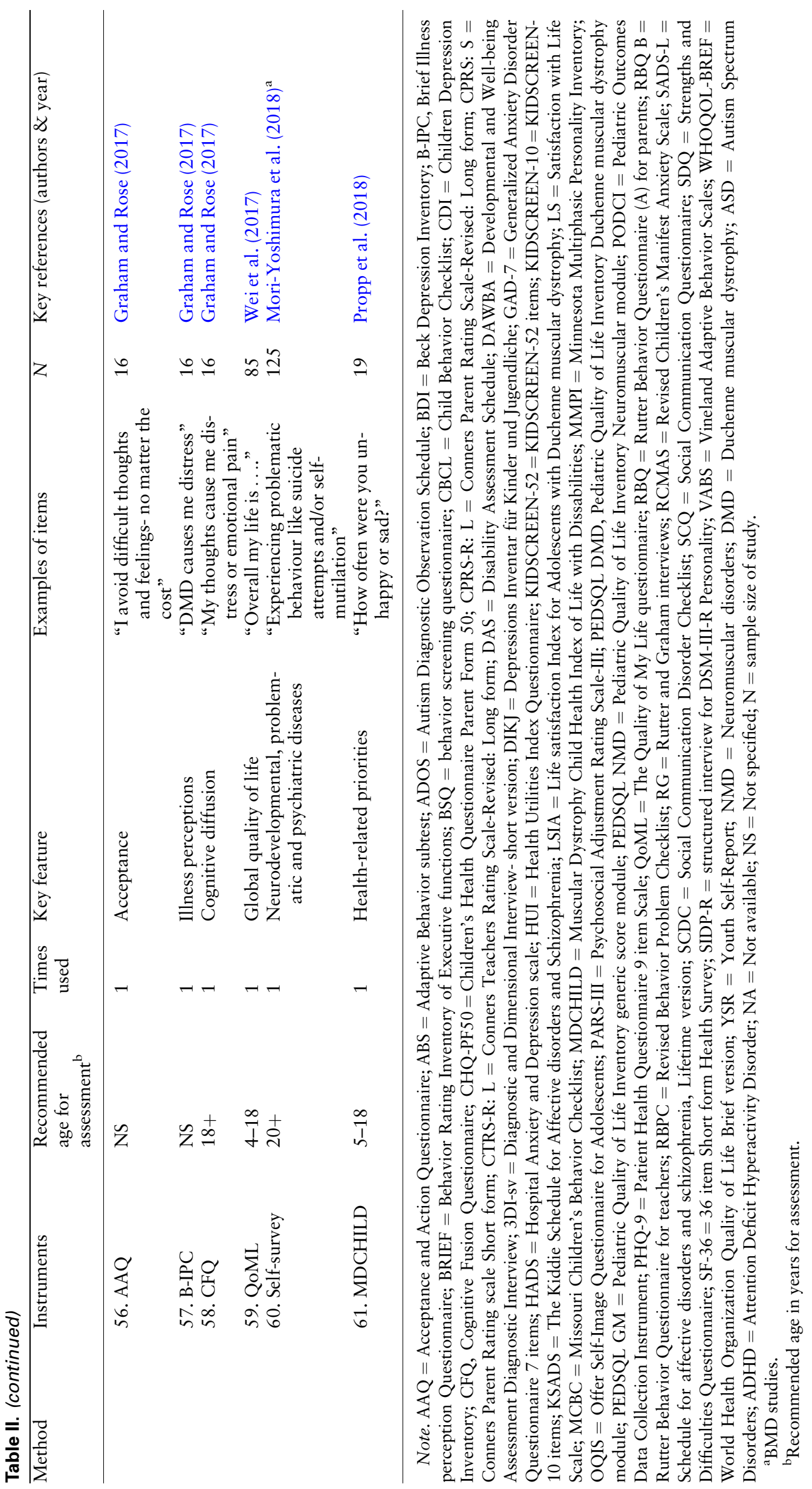


Table III. Excluded Instruments for Final Evaluation

\begin{tabular}{lccc}
\hline Instruments & $\begin{array}{c}\text { Clinical } \\
\text { observations }\end{array}$ & $\begin{array}{c}\text { (Semi) structured } \\
\text { clinical } \\
\text { interviews }\end{array}$ & Informant-ratings
\end{tabular}

1. ADOS

$\mathrm{x}$

2. $\mathrm{RG}$

3. BSQ

4. DAS

5. SADS-L

6. SIDP-R

7. Three wishes

8. Open- and structured questions on bodily functions, social participation and QOL

9. VABS

10. KSADS

11. Open-and structured questions on important topics for DMD

12. DAWBA

13. 3Di-sv

14. $\mathrm{RBQ}(\mathrm{A})$

15. RBQ (B)

16. $\mathrm{MCBC}$

17. RBPC

18. BRIEF

19. SCQ

20. CTRS-R: L

21. HUI

22. CPRS: $S$

23. CPRS: L

24. SCDC

25. QoML

26. MMPI

27. SWLS

28. RCMAS

29. CDI

30. DISABKIDS

31. DIKJ

32. BDI

33. HADS

34. AAQ

35. B-IPC

36. CFQ

37. Self-survey

38. MDCHILD

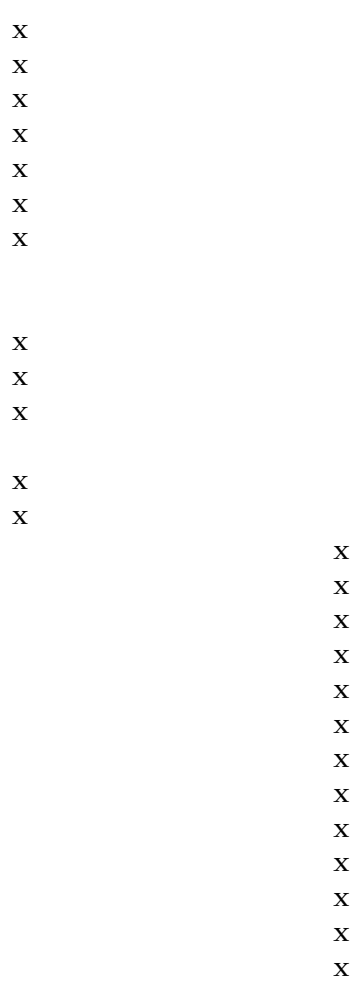

Note. AAQ $=$ Acceptance and Action Questionnaire; ADOS = Autism Diagnostic Observation Schedule; BDI $=$ Beck Depression Inventory; B-IPC = Brief Illness perception Questionnaire; BRIEF = Behavior Rating Inventory of Executive functions; BSQ $=$ behavior screening questionnaire; CDI = Children Depression Inventory; CFQ = Cognitive Fusion Questionnaire; CPRS-R: $L=$ Conners Parent Rating Scale-Revised: Long form; CPRS: S = Conners Parent Rating scale Short form; CTRS-R: L = Conners Teachers Rating Scale-Revised: Long form; DAS = Disability Assessment Schedule; DAWBA = Developmental and Well-being Assessment Diagnostic Interview; 3DI-sv = Diagnostic and Dimensional Interview- short version; DIKJ = Depressions Inventar für Kinder und Jugendliche; HADS = Hospital Anxiety and Depression scale; HUI = Health Utilities Index Questionnaire; KSADS = The Kiddie Schedule for Affective disorders and Schizophrenia; $\mathrm{MCBC}=$ Missouri Children's Behavior Checklist; MDCHILD = Muscular Dystrophy Child Health Index of Life with Dissabilities; MMPI = Minnesota Multiphasic Personality Inventory; QoML = The Quality of My Life questionnaire; RBQ = Rutter Behavior Questionnaire (A) for parents; RBQ B = Rutter Behavior Questionnaire for teachers; RBPC = Revised Behavior Problem Checklist; RG = Rutter and Graham interviews; RCMAS = Revised Children's Manifest Anxiety Scale; SADS-L = Schedule for affective disorders and schizophrenia, Lifetime version; SCDC = Social Communication Disorder Checklist; SCQ = Social Communication Questionnaire; SIDP-R = structured interview for DSMIII-R Personality; VABS = Vineland Adaptive Behavior Scales.

\section{Psychometric Properties of Included Instruments}

Table IV summarizes the psychometric properties of the 16 reviewed instruments. Values of Table IV are psychometric results of the total scale. Subscale information of the instruments is not included. The different forms (i.e., informant-rating and self-rating) of the KIDSCREEN, the Pediatric Quality of Life inventory general module (PedsQL GM), the PedsQL neuromuscular module (PedsQL NMM), and the PedsQL Duchenne module (PedsQL DMD) were 
Table IV. Psychometric Properties of Included Instruments

\begin{tabular}{|c|c|c|c|c|c|c|c|}
\hline Method & Instrument & $\begin{array}{c}\text { Internal } \\
\text { consistency }\end{array}$ & $\begin{array}{c}\text { Test- retest } \\
\text { reliability }\end{array}$ & $\begin{array}{c}\text { Inter-rater } \\
\text { reliability }\end{array}$ & $\begin{array}{c}\text { Convergent } \\
\text { validity }\end{array}$ & $\begin{array}{l}\text { Construct } \\
\text { validity }\end{array}$ & Responsiveness \\
\hline \multirow[t]{5}{*}{ Informant-ratings } & 1. PARS-III & + & ? & ? & + & + & ? \\
\hline & 2. $\mathrm{CBCL}$ & $?$ & $?$ & $\pm /-$ & $+/ \pm$ & $?$ & $?$ \\
\hline & 3. PODCI & ? & ? & $?$ & + & ? & ? \\
\hline & 4. CHQ-PF50 & \pm & ? & ? & $?$ & $?$ & $?$ \\
\hline & 5. ABS & ? & $?$ & $?$ & ? & $?$ & - \\
\hline \multirow[t]{6}{*}{ Self-ratings } & 6. OSIQ & + & ? & ? & $?$ & ? & ? \\
\hline & 7. LSIA & + & ? & ? & + & $?$ & $?$ \\
\hline & 8. YSR & $?$ & $?$ & $\pm /-$ & $?$ & $?$ & $?$ \\
\hline & 9. SDQ & ? & ? & ? & $+/ \pm$ & ? & ? \\
\hline & 10. SF-36 & $?$ & $?$ & ? & $\pm /-$ & $?$ & $?$ \\
\hline & 11. WHOQOL-BREF & $?$ & $?$ & $?$ & $\pm /-$ & $?$ & $?$ \\
\hline \multirow{11}{*}{$\begin{array}{l}\text { Informant- and } \\
\text { self-ratings }\end{array}$} & 12. PEDSQL GM & & & & & & \\
\hline & Informant form & + & ? & - & + & $?$ & + \\
\hline & $\begin{array}{l}\text { Self-rating form } \\
\text { 13. PEDSQL NMM }\end{array}$ & $+/ \pm$ & $?$ & - & $?$ & $?$ & + \\
\hline & Informant form & + & $+/ \pm$ & $\pm /-$ & ? & ? & + \\
\hline & $\begin{array}{l}\text { Self-rating form } \\
\text { 14. PEDSQL DMD }\end{array}$ & + & $\pm /-$ & $\pm /-$ & $?$ & - & - \\
\hline & Informant form & $+/ \pm$ & ? & - & $?$ & $?$ & ? \\
\hline & $\begin{array}{l}\text { Self-rating form } \\
\text { 15. KIDSCREEN-52 }\end{array}$ & \pm & $?$ & - & $?$ & $?$ & $?$ \\
\hline & Informant form & $?$ & ? & $\pm /-$ & ? & ? & ? \\
\hline & $\begin{array}{l}\text { Self-rating form } \\
\text { 16. KIDSCREEN-10 }\end{array}$ & $?$ & $?$ & $\pm /-$ & $?$ & $?$ & $?$ \\
\hline & Informant form & \pm & $?$ & ? & $?$ & ? & ? \\
\hline & Self-rating form & \pm & $?$ & $?$ & $?$ & ? & ? \\
\hline
\end{tabular}

Note. ABS = Adaptive Behavior subtest of Bayley; CBCL = Child Behavior Checklist; CHQ-PF50=Children's Health Questionnaire Parent Form 50; KIDSCREEN-52 = KIDSCREEN 52 items; KIDSCREEN-10= KIDSCREEN 10 items; LSIA = Life satisfaction Index for Adolescents with Duchenne muscular dystrophy; OSIQ = Offer Self-Image Questionnaire for Adolescents; PARS-III = Psychosocial Adjustment Rating Scale-III; PEDSQL DMD = Pediatric Quality of Life Inventory Duchenne Muscular Dystrophy Module; PEDSQL GM = Pediatric Quality of Life Inventory Generic Module; PEDSQL NMM = Pediatric Quality of Life Inventory Neuromuscular Module; PODCI $=$ Pediatric Outcomes Data Collection Instrument; SDQ = Strengths and Difficulties Questionnaire; SF-36=36 item Short form Health Survey; WHOQOL-BREF $=$ World Health Organization Quality of Life Brief version; YSR = Youth Self-Report; $+=$ Sufficient; $\pm=$ moderate; - = insufficient; ? = Unknown/unclear.

assessed separately. As can been seen in Table IV, most psychometric information was available from the PARS-III, the PedsQL GM, and the PedsQL NMM. The PARS-III had good internal consistency (Cronbach's $\alpha=0.91)$, convergent validity $(r=$ -0.65 ), and construct validity (factor analysis confirmed structure of instrument; comparative fit Index: 0.96, the standardized root mean square residual [SRMR]: 0.06). No information on inter-rater reliability, test-retest reliability, and responsiveness was available.

The PedsQL GM informant-rating form had good internal consistency (Cronbach's $\alpha=0.83$ ) and the internal consistency of the PedsQL GM self-rating form was moderate to good (Cronbach's $\alpha$ ranged between 0.73 and 0.87$)$. The inter-rater reliability of both forms was insufficient (informant-rating and selfrating ICC ranged between 0.20 and 0.64 , and $r=0.54)$. Convergent validity was good for the informant-rating form $(r=0.72)$ but unknown for the self-rating form. Responsiveness was good for both forms (informant-rating: $\quad p<.001$, self-rating: $p=.04)$. No information was available on test-retest reliability and construct validity of the informantrating form and self-rating form.The PedsQL NMM informant-rating form and self-rating form had good internal consistency (Cronbach's $\alpha$ informant-rating form: $0.86-0.87$ and self-rating form: 0.81-0.92). Test-retest reliability of the informant-rating form was sufficient $(r=0.85-0.88)$ and moderate to insufficient $(r=0.66-0.75)$ for the self-rating form. The inter-rater reliability of both forms ranged from moderate to insufficient (ICC ranged between 0.51 and 0.78). Convergent validity was good for the informant-rating form $(r=0.60-0.71)$ and the selfrating form $(r=0.65-0.67)$. No information was available on construct validity of the informant-rating form. Construct validity was insufficient for the selfrating form, since the structure of the form was not confirmed by principal component analysis. 
Table V. Content Validity and Applicability of Included Instruments

\begin{tabular}{|c|c|c|c|c|c|c|c|c|c|}
\hline \multirow[t]{2}{*}{ Method } & \multirow[t]{2}{*}{ Instrument } & \multicolumn{5}{|c|}{ Content validity } & \multicolumn{3}{|c|}{ Applicability } \\
\hline & & Aim & Population & Concepts & $\begin{array}{l}\text { Relevant } \\
\text { items }\end{array}$ & $\begin{array}{l}\text { Clear } \\
\text { Items }\end{array}$ & $\begin{array}{l}\text { Available } \\
\text { by }\end{array}$ & $\begin{array}{l}\text { Duration } \\
\text { in min }\end{array}$ & $\begin{array}{l}\text { Different } \\
\text { languages }\end{array}$ \\
\hline \multirow[t]{5}{*}{ Informant-ratings } & 1.PARS-III & + & - & + & + & + & Author & $5-10$ & Yes \\
\hline & 2. CBCL & + & - & + & \pm & \pm & Publisher & $15-20$ & Yes \\
\hline & 3. PODCI & + & - & + & + & \pm & Website & 20 & Yes \\
\hline & 4. CHQ-PF50 & + & - & + & + & \pm & Author & $10-15$ & Yes \\
\hline & 5. ABS & + & - & + & $?$ & $?$ & Publisher & $50^{\mathrm{b}}$ & Yes \\
\hline \multirow{6}{*}{ Self-ratings } & 6. OSIQ & + & - & + & \pm & \pm & Author & $40-50$ & Yes \\
\hline & 7. LSIA & + & + & + & + & + & Author & $7-10$ & Yes \\
\hline & 8. YSR & + & - & + & \pm & + & Publisher & $15-20$ & Yes \\
\hline & 9. SDQ & + & - & + & \pm & \pm & Website & $5-10$ & Yes \\
\hline & 10. SF-36 & + & - & + & \pm & \pm & Website & 9 & Yes \\
\hline & 11. WHOQOL-BREF & + & - & + & + & \pm & Website & $10-15$ & Yes \\
\hline \multirow{11}{*}{$\begin{array}{l}\text { Informant- and } \\
\text { self-ratings }\end{array}$} & 12. PEDSQL GM & & & & & & & & \\
\hline & Informant form & + & - & + & + & + & Website & $15-20$ & Yes \\
\hline & $\begin{array}{l}\text { Self-rating form } \\
\text { 13. PEDSQL NMM }\end{array}$ & + & - & + & + & + & Website & $15-20$ & Yes \\
\hline & Informant form & + & $-{ }^{\mathrm{a}}$ & + & + & + & Website & 10 & Yes \\
\hline & $\begin{array}{l}\text { Self-rating form } \\
\text { 14. PEDSQL DMD }\end{array}$ & + & $-{ }^{\mathrm{a}}$ & \pm & - & - & Website & 10 & Yes \\
\hline & Informant form & + & + & + & + & + & Website & 5 & Yes \\
\hline & $\begin{array}{l}\text { Self-rating form } \\
\text { 15. KIDSCREEN-52 }\end{array}$ & + & + & + & + & + & Website & 5 & Yes \\
\hline & Informant form & + & - & + & \pm & + & Website & $15-20$ & Yes \\
\hline & $\begin{array}{l}\text { Self-rating form } \\
\text { 16. KIDSCREEN-10 }\end{array}$ & + & - & + & \pm & + & Website & $15-20$ & Yes \\
\hline & Informant form & + & - & + & + & + & Website & 5 & Yes \\
\hline & Self-rating form & + & - & + & + & + & Website & 5 & Yes \\
\hline
\end{tabular}

Note. $\mathrm{ABS}=$ Adaptive Behavior subtest of Bayley; CBCL = Child Behavior Checklist; CHQ-PF50= Children's Health Questionnaire Parent Form 50; KIDSCREEN-52= KIDSCREEN 52 items; KIDSCREEN-10= KIDSCREEN 10 items; LSIA = Life satisfaction Index for Adolescents with Duchenne muscular dystrophy; OSIQ = Offer Self-Image Questionnaire for Adolescents; PARS-III = Psychosocial Adjustment Rating Scale-III; PEDSQL DMD = Pediatric Quality of Life Inventory Duchenne muscular dystrophy module; PEDSQL GM = Pediatric Quality of Life Inventory Generic Module; PEDSQL NMM = Pediatric Quality of Life Inventory Neuromuscular Module; PODCI $=$ Pediatric Outcomes Data Collection Instrument; SDQ = Strengths and Difficulties Questionnaire; SF-36=36 item Short form Health Survey; WHOQOL-BREF $=$ World Health Organization Quality of Life Brief version; YSR $=$ Youth Self-Report; $+=$ Yes incorporated in the instrument, - = Not incorporated in the instrument; $\pm=$ doubtful; ? = Unknown/unclear; Aim = Aim of instrument is clarified; Population = Items of instrument are specified for dystrophinopathy; Concepts = Relevant concepts of the instruments are clarified and will be measured by separate subscales; Relevant items = Items of instrument reflect areas important for dystrophinopathy; Clear items = Items are simple and contain no jargon terms or two questions at the same time.

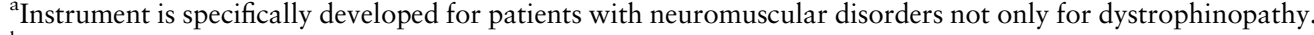

${ }^{b}$ Duration of assessment is for total Bayley scale.

Responsiveness was good for the informant-rating form $(p=.005)$ but insufficient for the self-rating form $(p=.77)$.

\section{Content Validity and Applicability of Included Instruments}

Results of content validity and applicability of the 16 reviewed instruments are displayed in Table V. All instruments met criterion 1 , signifying that instruments had specific measurement aims. Only two instruments were specifically developed for dystrophinopathy and met criterion 2: the Life Satisfaction Index for Adolescent with Duchenne muscular dystrophy (LSIA) and the PedsQL DMD. All instruments consisted of specified concepts, measured by separate subscales and items (criterion 3), except for the
PedsQL NMM self-rating form. Subscales of the PedsQL NMM self-rating form contain nondistinctive items, for instance, "it is hard for me to tell the doctors and nurses how I feel" and "it is hard for me to ask doctors and nurses questions." All instruments met criterion 4 and measured a degree of behavioral or psychosocial functioning relevant for the dystrophinopathy population, though items of two instruments (i.e., Child Behavior Checklist [CBCL] Offer Self-Image Questionnaire [OSIQ]) are less applicable in dystrophinopathy due to the progressive physical immobility. Less applicable items are for example can't sit still, being restless' (CBCL-ADHD subscale), "runs away from home" (CBCL-rule breaking behavior subscale), or "I love the recent changes in my body" (OSIQ). Several instruments did not fulfill 
criterion 5, since the items contain more than one question at the same time. In addition, items of the PedsQL NMM self-rating form for toddlers and young children (i.e., "hard to gain or lose weight"; do not have the equipment one needs) are not applicable or too difficult to understand. With regard to the applicability of the instruments, it was found that all instruments were available in English. Most instruments $(n=9)$ were freely available by website, four by author, and three by publisher. Administration time of nine instruments was $<10 \mathrm{~min}$ and of seven instruments the time varied from 10 to $50 \mathrm{~min}$.

\section{Discussion}

The purpose of this systematic review was to provide an overview of instruments used to assess behavioral and psychosocial functioning of patients with DMD and $\mathrm{BMD}$, as well as to review the psychometric properties and applicability of these instruments. A total of 61 different instruments have been used in 51 DMD studies and 3 BMD studies. Our review showed that most previous studies provide limited psychometric information. The majority of instruments being used are informant-rating and self-rating instruments. The most common used ( $N=11$ studies) is the CBCL (Achenbach, 1991), but only two studies reported psychometric information on convergent validity (ranging from poor to moderate) and inter-rater reliability (ranging from moderate to good) (Colombo et al., 2017; Fee \& Hinton, 2011). Additionally, the content validity of the CBCL is less sufficient for patients with motor impairments when questions involve normal motor abilities. This can result in underidentification of behavioral comorbidities due to lower scores in for instance hyperactive or oppositional, aggressive behavior (Cook \& Beckman, 2006). Furthermore, the CBCL is developed for screening of various behavioral and emotional symptoms and is not intended to be a diagnostic instrument for establishing definite DSM-5 (American Psychiatric Association, 2013) diagnoses, such as ADHD (Goodman \& Scott, 1999). To accurately diagnose $\mathrm{ADHD}$ clinicians should be able to differentiate symptoms of inattention, hyperactivity, and impulsivity. The symptom items of the CBCL-ADHD subscale have no conceptual link with the diagnostic criteria for ADHD (Goodman \& Scott, 1999). Other instruments, for instance, the Conners Parent Rating Scale-Revised (CPRS-R) or the SDQ differentiate and ascertain ADHD symptoms more accurately. Since the items of the CPRS-R and SDQ subscales are selected on the basis of nosologically concepts (i.e., DSM criteria and International Statistical Classification of diseases and related Health Problems: ICD-10) as well as on factor analysis (Gianarris, Golden, \& Greene,
2001; Goodman \& Scott, 1999; Hall et al., 2019). This likely explains that Colombo et al. (2017) recently found an ADHD comorbidity of $0 \%$ in their DMD sample based on CBCL screening, while Banihani et al. (2015) found a prevalence rate as high as $32 \%$ for ADHD using CPRS-R for ADHD. These data confirm that the prevalence rates of behavioral comorbidities in DMD as previously reported largely depend on the instruments that were used and should, therefore, be considered with caution. The majority of previous studies used instruments with unevaluated or poor psychometric properties, or instruments that are not developed to differentiate behavioral symptoms.

\section{Psychometric Properties of Included Instruments}

For the current systematic review disease specific psychometric information was available for 21 DMD studies with 16 instruments being reviewed, including both informant-ratings and self-ratings. The $33 \mathrm{ex}-$ cluded studies used significantly different instruments including clinical observations and semistructured interviews, in addition to informant-rating and selfrating instruments. Thereby, this review only describes psychometric properties of informant-rating and selfrating instruments for DMD. With regard to the psychometric properties of the included instruments, more in depth evaluation was found for the PARS-III, the PedsQL GM, and the PedsQL NMM. The PARSIII proves to be an adequate instrument and is therefore recommended in the standards of care for DMD (Birnkrant et al., 2018). However, additional validation by replication of reported psychometric results is recommended as well as data on inter-rater reliability, test-retest reliability, and responsiveness. The PedsQL GM informant-rating and self-rating form have relatively good properties, both having only poor interrater reliability. Data on PedsQL NMM informantrating form varies in previous studies and it inter-rater reliability is low. Moderate to poor psychometric results are noted for the PedsQL NMM self-rating form, suggesting that it is no valid instrument for DMD. The inter-rater reliability of both PedsQL modules (GM and NMM) are low, reflecting a discrepancy between patients and their parents/caregivers. This is in line with previous studies showing that parents/ caregivers overestimate the magnitude of problems due to their own concerns and perceptions of the illness (Bray, Bundy, Ryan, North, \& Everett, 2010b; Solden, Guildea, Antao, Street, \& Sibert, 1999). This could explain the notable difference between behavioral and psychosocial problems reported by patients and caregivers (Davis et al., 2010; Houwen-van Opstal, Jansen, van Alfen, \& de Groot, 2014; Lim, Velozo, \& Bendixen, 2014). Additional validation on psychometric properties of both PedsQL modules and 
their separate forms is necessary, before using them for clinical or research trials. With respect to the three (SDQ, GAD-7, and PHQ-9) remaining recommended instruments of the recently published standards of care for DMD (Birnkrant et al., 2018), two instruments (GAD-7 and PHQ-9) have no disease specific psychometric information. However, previous studies reported that the GAD-7 is a valid instrument for screening of generalized anxiety disorders as well as for panic, social anxiety, and post-traumatic stress disorders (Kroenke, Spitzer, Williams, Monahan, \& Löwe, 2007; Spitzer et al., 2006). Nevertheless, the GAD-7 provides only a probable diagnosis and further evaluation is necessary to diagnose anxiety. Furthermore, the psychometric properties of the PHQ9 have been evaluated by multiple clinical studies. This instrument seems favorable in screening for depression in primary and mental health care and is equal or superior to other depression measures (Kroenke, Spitzer, Williams, \& Löwe, 2010). However, previous studies on the GAD-7 and the PHQ-9 evaluated the reliability and validity of these instruments in adult patients and the usefulness for DMD should be assessed accordingly. The third instrument, the SDQ, poses limited psychometric information and Colombo et al. (2017) showed that the SDQ has a moderate to good validity in $N=47$ males with DMD. The SDQ has been extensively evaluated in children and adolescents with or without a chronic illness and it is believed that it is a reliable and valid screener for psychiatric comorbidities (Bourdon, Goodman, Rae, Simpson, \& Koretz, 2005; Goodman 2001; Hysing, Elgen, Gillberg, Lie, \& Lundervold, 2007; Hysing, Elgen, Gillberg, \& Lundervold, 2009; Klasen, Woerner, Rothenberger, \& Goodman, 2003; Smedje, Broman, Hetta, \& Von Knorring, 1999). In addition, a higher specificity of the SDQ informantrating $(0.85)$ has been noted compared to the $\mathrm{CBCL}$ $(0.72)$, meaning that the SDQ will result in less overestimation of true behavioral comorbidity. Overall, the SDQ should be considered as a valid and robust instrument for future research and clinical settings, though care should be taken when using the SDQ algorithm to screen for ADHD comorbidity (Hall et al., 2019). Further evaluation of the SDQ psychometric properties for the dystrophinopathy population is recommended.

\section{Content Validity and Applicability of Included Instruments}

The current review systematically evaluated content validity and applicability of the 16 included instruments. Only the LSIA and PedsQL DMD fulfilled the five content validity criteria and may thus be suitable for DMD care. However, our psychometric results revealed sufficient and reliable results for the LSIA, but insufficient results for the PedsQL DMD. Additional research on the reliability of both instruments is recommended. Furthermore, of the 16 included instruments, the majority had items that were (1) limited or not applicable to the dystrophinopathy population, (2) or too difficult to answer for patients or parents/caregivers. In addition, the majority of the included instruments were relatively easily accessible by website and could be filled in quickly $(<10 \mathrm{~min})$.

\section{Limitations}

This review was designed to capture all behavioral and psychosocial instruments currently used in crosssectional and longitudinal studies. As a consequence, potentially good instruments used in studies with other designs (e.g., case-report or conference abstracts) have been excluded. Furthermore, we excluded studies with possible adequate instruments when no separate information was available for the dystrophinopathy population. Excluded studies, for instance, used the Autism Diagnostic InterviewRevised (Hinton et al., 2009), Experience Sampling Method (Bray, Bundy, Ryan, \& North, 2010a), California Psychological Inventory (Fowler et al., 1997), Personal Assessment Inventory-Depression (Fowler et al., 1997), Child Health QuestionnaireChild form-87 (Wilson et al., 2006), Multidimensional Scale of Perceived Social Support (Wilson et al.2006), Quality of Life Profile Questionnaire (Dany et al., 2015, 2017), and Strips of Life with Emoticons Questionnaire (Orcesi et al., 2014) in patients with other neuromuscular disorders (e.g., spinal muscular atrophy, myopathy, and giant axonal neuropathy). An important strength of our study is the use of the psychometric property criteria. However, at the same time this approach limits the finding of adequate instruments. Previous studies, for instance, used less stringent criteria to assess interrater reliability between the informant-rating and selfrating form of the PedsQL GM and PedsQL NMM (Davis et al., 2010; Uzark et al., 2012). Despite the less stringent criteria, the outcomes of Davis et al. (2010) and Uzark et al. (2012) were in line with the findings of the current review concerning the poor inter-reliability between the informant-rating and selfrating form of both PedsQL modules. Furthermore, for final evaluation, we excluded studies that reported no information on psychometric properties, content validity, and applicability for the dystrophinopathy population. Therefore, all BMD studies were excluded and generalizations of our results regarding the entire dystrophinopathy population should be made with caution. Additionally, the MDCHILD could not be included in the current review, since no information was available on psychometric properties for the dystrophinopathy population (Propp et al., 2018). 


\section{Clinical Recommendations}

The current review provides no gold standard for methods of assessment, but based on the findings the PARS-III, LSIA, and PedsQL GM are potentially valid instruments for screening of psychosocial problems in DMD. Nonetheless, when using the PedsQL GM we recommend to administer both the informant-rating and self-rating form, to limit the error variance caused by disagreements between patients and parents/caregivers perspectives.

Appropriate instruments for screening of behavioral problems in DMD may be the SDQ for pediatric patients and the GAD-7 and PHQ-9 for adult patients. Additional research on psychometric properties of these instruments for DMD as well for BMD is crucial and definite outcomes of these screening instruments should be considered with caution.

For definite diagnostics, we recommend to use the gold standard assessment method for behavioral disorders. This is referred to as the multimethod, multisource, multisetting assessment, and implies using different assessment methods (e.g., behavioral observations, structured clinical interviews, informantratings, and self-ratings), different sources (e.g., patients, parents/caregivers, teachers, and clinicians), and different settings (e.g. at home, school, and the clinic) to get a comprehensive representation of the child's or adolescent's behavioral, emotional, and psychosocial functioning (Whitcomb \& Merrel, 2013). We believe that this method is particularly important for the ageing high-risk dystrophinopathy population, whereof $20 \%$ of patients have more than one comorbid behavioral disorder (Banihani et al., 2015; Hendriksen \& Vles, 2008; Hinton et al., 2009; Pane et al., 2012; Ricotti et al., 2016; Steele et al., 2008; Thompson et al., 1992; Uzark et al., 2012). This multimethod-, source-, setting assessment reduces error variance, resulting in less underidentification of behavioral comorbidities in this high-risk population. Each neuromuscular team should include a mental health professional (psychologist or psychiatrist) with experience in neurodevelopmental, behavioral, and medical conditions, who routinely screens a patients' behavioral and psychosocial functioning every $2-3$ years and applies this multimethod-, source, setting assessment when necessary (Birnkrant et al., 2018). Adequate and early detection of behavioral comorbidities can greatly facilitate targeted treatment. We know, for instance, that in the general ADHD population, underdiagnosed ADHD problems put patients at higher risk for educational underachievement, behavioral comorbidities like depression, impairments in social relations, and a reduced quality of life, that can extend throughout adulthood (Hoza, 2007; Pine, Cohen, Gurley, Brook, \& Ma, 1998; Woodward \& Fergusson, 2001). According to our review, only one previous DMD study applied this multimethod-, source-, setting assessment using the DSM-IV criteria together with two screening instruments, the Conners Parent and Conners Teacher Rating Scales, to diagnose ADHD comorbidity in their DMD sample (Banihani et al., 2015). Two additional studies administered this method partly and evaluated behavioral problems using structured interviews such as the DAWBA, ADOS, and $3 \mathrm{Di}-\mathrm{S}_{\mathrm{v}}$ in addition to multiple informant-rating and self-rating instruments (Colombo et al., 2017; Ricotti et al., 2016).

\section{Conclusion}

The present review describes a wide variety of instruments used to assess behavioral and psychosocial functioning in the dystrophinopathy population. We argue that the interpretation of behavioral disorders and psychosocial problems as reported in previous studies using these instruments should be taken with caution. Our review shows that the PARS-III, PedsQL GM, and LSIA are potentially valid instruments for psychosocial screening. The SDQ, GAD-7, and PHQ-9 may be appropriate instruments for behavioral screening. Other screening instruments that lack psychometric data for the dystrophinopathy population may be appropriate as well, but their outcomes should be considered with caution. Additional psychometric data on instruments for screening of behavioral and psychosocial problems is necessary. Since the ageing dystrophinopathy population is confronted with long-lasting or new mental health issues that negatively influence their quality of life. A mental health professional should routinely screen a patient's behavioral and psychosocial functioning, preferably every 2-3 years and particularly during transitioning (e.g., childhood to adolescence and adolescence to adulthood) (Birnkrant et al., 2018). For definite diagnostics, we believe that a multimethod-, source-, setting assessment is the most appropriate method of assessment in this unique population. Given the complexity of behavioral comorbidities, clinicians and researchers should never diagnose conditions based on the result of one screening instrument.

\section{Supplementary Data}

Supplementary data can be found at: https://academic.oup. com/jpepsy.

\section{Acknowledgment}

The authors would like to thank Spieren voor Spieren and Duchenne Parent Project NL for their funding. Special thanks to mw. I. Gijselhart for her help in creating the searches.

\section{Funding}

This work was supported by Spieren voor Spieren Foundation (grant number SvS15-) and Duchenne Parent 
Project NL. All reimbursements were received by Kempenhaeghe, Heeze, The Netherlands. No personal financial benefits were received.

Conflict of interest: The authors declared no potential conflicts of interest with respect to the research, authorship and/ or publication of this article.

\section{References}

Abbott, D., \& Carpenter, J. (2015). “The Things that are Inside of You Are Horrible": Children and young men with Duchenne muscular dystrophy talk about the impact of living with a long-term condition. Child and Care in Practice, 21, 67-77.

Achenbach, T. M. (1991). Manual for the child behavior checklist/4-18 and 1991 profile. Burlington, VT: University of Vermont, Department of Psychiatry.

American Psychiatric Association. (2013). Diagnostic and statistical manual of mental disorders $\left(D S M-5^{\circledR}\right)$. Arlington, VA: American Psychiatric Publication.

Baiardini, I., Minetti, C., Bonifacino, S., Porcu, A., Klersy, C., Petralia, P., ... Braido, F. (2011). Quality of life in Duchenne muscular dystrophy: The subjective impact on children and parents. Journal of Child Neurology, 26, 707-713. doi:10.1177/0883073810389043

Banihani, R., Smile, S., Yoon, G., Dupuis, A., Mosleh, M., Snider, A., \& McAdam, L. (2015). Cognitive and neurobehavioral profile in boys with Duchenne muscular dystrophy. Journal of Child Neurology, 30, 1472-1482. doi:10.1177/0883073815570154

Bendixen, R. M., Senesac, C., Lott, D. J., \& Vandenborne, K. (2012). Participation and quality of life in children with Duchenne muscular dystrophy using the International Classification of Functioning, Disability, and Health. Health and Quality of Life Outcomes, 10, 43. doi:10.1186/1477-7525-10-43

Birnkrant, D. J., Bushby, K., Bann, C. M., Apkon, S. D., Blackwell, A., \& Colvin, M. K. (2018). Diagnosis and management of Duchenne muscular dystrophy, part 3: Primary care, emergency management, psychosocial care, and transitions of care across the lifespan. Lancet Neurology, 17, 445-455.

Bourdon, K. H., Goodman, R., Rae, D. S., Simpson, G., \& Koretz, D. S. (2005). The strengths and difficulties questionnaire: US normative data and psychometric properties. Journal of the American Academy of Child \& Adolescent Psychiatry, 44, 557-564.

Bray, P., Bundy, A. C., Ryan, M. M., \& North, K. N. (2010a). Feasibility of a computerized method to measure quality of "everyday" life in children with neuromuscular disorders. Physical \& Occupational Therapy Pediatrics, 30, 43-53. doi:10.3109/01942630903294687

Bray, P., Bundy, A. C., Ryan, M. M., North, K. N., \& Burns, J. (2011). Health status of boys with Duchenne muscular dystrophy: A parent's perspective. Journal of Paediatrics and Child Health, 47, 557-562. doi:10.1111/j.14401754.2011.02022.x

Bray, P., Bundy, A. C., Ryan, M. M., North, K. N., \& Everett, A. (2010b). Health-related quality of life in boys with Duchenne muscular dystrophy: Agreement between parents and their sons. Journal of Child Neurology, 25, 1188-1194. doi:10.1177/0883073809357624

Colombo, P., Nobile, M., Tesei, A., Civati, F., Gandossini, S., Mani, E., ... D’Angelo, G. (2017). Assessing mental health in boys with Duchenne muscular dystrophy: Emotional, behavioural and neurodevelopmental profile in an Italian clinical sample. European Journal of Paediatric Neurology, 21, 639-647. doi:http://dx.doi.org/10.1016/j. ejpn.2017.02.007

Connolly, A. M., Florence, J. M., Cradock, M. M., Eagle, M., Flanigan, K. M., McDonald, C. M., ... Mendell, J. R. (2014). One year outcome of boys with Duchenne muscular dystrophy using the Bayley-III scales of infant and toddler development. Pediatric Neurology, 50, 557-563. doi:10.1016/j.pediatrneurol.2014.02.006

Cook, D. A., \& Beckman, T. J. (2006). Current concepts in validity and reliability for psychometric instruments: Theory and application. The American Journal of Medicine, 1, 166.e7-16.

Cyrulnik, S. E., Fee, R. J., Batchelder, A., Kiefel, J., Goldstein, E., \& Hinton, V. J. (2008). Cognitive and adaptive deficits in young children with Duchenne muscular dystrophy (DMD). Journal of the International Neuropsychological Society, 14, 853-861. doi:10.1017/ S135561770808106X.

Dany, A., Barbe, C., Rapin, A., Réveillère, C., Hardouin, J.B., Morrone, I., ... Boyer, F. C. (2015). Construction of a Quality of Life Questionnaire for slowly progressive neuromuscular disease. Quality of Life Research, 24, 2615-2623.

Dany, A., Rapin, A., Lavrard, B., Saoût, V., Réveillère, C., Bassez, G., ... Boyer, F. C. (2017). The quality of life in genetic neuromuscular disease questionnaire: Rasch validation of the French version. Muscle and Nerve, 56, 1085-1091. doi:http://dx.doi.org/10.1002/mus.25598.

Davis, S. E., Hynan, L. S., Limbers, C. A., Andersen, C. M., Greene, M. C., Varni, J. W., \& Iannaccone, S. T. (2010). The PedsQL in pediatric patients with Duchenne muscular dystrophy: Feasibility, reliability, and validity of the Pediatric Quality of Life Inventory Neuromuscular Module and Generic Core Scales. Journal of Clinical Neuromuscular Disease, 11, 97-109. doi:10.1097/ CND.0b013e3181c5053b

Donald, K. A., Mathema, H., Thomas, K. G., \& Wilmshurst, J. M. (2011). Intellectual and behavioral functioning in a South African cohort of boys with Duchenne muscular dystrophy. Journal of Child Neurology, 26, 963-969. doi:10.1177/0883073811399149

Donders, J., \& Taneja, C. (2009). Neurobehavioral characteristics of children with Duchenne muscular dystrophy. Child Neuropsychology, 15, 295-304. doi:10.1080/ 09297040802665777

Doorenweerd, N., Mahfouz, A., van Putten, M., Kaliyaperumal, R., t'Hoen, P.A., \& Hendriksen, J.G. (2017). Timing and localization of human dystrophin isoform expression provide insights into the cognitive phenotype of Duchenne muscular dystrophy. Science Report, 7, 12575.

Eggers, S., \& Zatz, M. (1998). Social adjustment in adult males affected with progressive muscular dystrophy. American Journal of Medical Genetics, 81, 4-12. 
Elsenbruch, S., Schmid, J., Lutz, S., Geers, B., \& Schara, U. (2013). Self-reported quality of life and depressive symptoms in children, adolescents, and adults with Duchenne muscular dystrophy: A cross-sectional survey study. Neuropediatrics, 44, 257-264. doi:10.1055/s-00331347935

Fee, R. J., \& Hinton, V. J. (2011). Resilience in children diagnosed with a chronic neuromuscular disorder. Journal of Developmental and Behavioral Pediatrics, 32, 644-650. doi:10.1097/DBP.0b013e318235d614

Fitzpatrick, C., \& Barry, C. (1986). Communication within families about Duchenne muscular dystrophy. Developmental Medicine and Child Neurology, 28, 596-599. doi:10.1111/j.1469-8749.1986.tb03901.x

Fowler, W. M. Jr, Abresch, R. T., Koch, T. R., Brewer, M. L., Bowden, R. K., \& Wanlass, R. L. (1997). Employment profiles in neuromuscular diseases. American Journal of Physical Medicine \& Rehabilitation, 76, 26-37.

Gianarris, W. J., Golden, C. J., \& Greene, L. (2001). The Conners'Parent Rating Scales: a critical review of the literature. Clinical Psychology Review, 21, 1061-1093.

Goodman, R. (2001). Psychometric properties of the strengths and difficulties questionnaire. Journal of the American Academy of Child \& Adolescent Psychiatry, 40, 1337-1345.

Goodman, R., \& Scott, S. (1999). Comparing the Strengths and Difficulties Questionnaire and the Child Behavior Checklist: is small beautiful? Journal of Abnormal Child Psychology, 27, 17-24.

Graham, C. D., \& Rose, M. R. (2017). What explains high life satisfaction in men living with Duchenne muscular dystrophy? A preliminary study to inform psychological intervention. Muscle and Nerve, 56, 163-166. doi:10.1002/ mus. 25495

Hall, C. L., Guo, B., Valentine, A. Z., Groom, M. J., Daley, D., Sayal, K., \& Hollis, C. (2019). The validity of the Strengths and Difficulties Questionnaire (SDQ) for children with ADHD symptoms. PloS One, 14, e0218518.

Harper, D. C. (1983). Personality correlates and degree of impairment in male adolescents with progressive and nonprogressive physical disorders. Journal of Clinical Psychology, 39, 859-867.

Hendriksen, J. G. M., Poysky, J. T., Schrans, D. G., Schouten, E. G., Aldenkamp, A. P., \& Vles, J. S. H. (2009). Psychosocial adjustment in males with Duchenne muscular dystrophy: Psychometric properties and clinical utility of a parent-report questionnaire. Journal of Pediatric Psychology, 34, 69-78. doi:10.1093/jpepsy/ jsn067

Hendriksen, J. G. M., \& Vles, J. S. H. (2008). Neuropsychiatric disorders in males with Duchenne muscular dystrophy: Frequency rate of attention-deficit hyperactivity disorder (ADHD), autism spectrum disorder, and obsessive-compulsive disorder. Journal of Child Neurology, 23, 477-481. doi:10.1177/ 0883073807309775

Hendriksen, R. G. F., Hoogland, G., Schipper, S., Hendriksen, J. G. M., Vles, J. S. H., \& Aalbers, M. W. (2015). A possible role of dystrophin in neuronal excitability: A review of the current literature. Neuroscience and Biobehavioral Reviews, 51, 255-262.
Hinton, V., De Vivo, D., Fee, R., Goldstein, E., \& Stern, Y. (2004). Investigation of poor academic achievement in children with Duchenne muscular dystrophy. Learning Disabilities Research and Practice, 19, 146-154.

Hinton, V. J., Cyrulnik, S. E., Fee, R. J., Batchelder, A., Kiefel, J. M., Goldstein, E. M., ... De Vivo, D. C. (2009). Association of autistic spectrum disorders with dystrophinopathies. Pediatric Neurology, 41, 339-346.

Hinton, V. J., Fee, R. J., De Vivo, D. C., \& Goldstein, E. (2007). Poor facial affect recognition among boys with Duchenne muscular dystrophy. Journal of Autism Developmental Disorders, 37, 1925-1933. doi:10.1007/ s10803-006-0325-5

Hinton, V. J., Nereo, N. E., Fee, R. J., \& Cyrulnik, S. E. (2006). Social behavior problems in boys with Duchenne muscular dystrophy. Journal of Developmental and Behavioral Pediatrics, 27, 470-476.

Houwen-van Opstal, S. L., Jansen, M., van Alfen, N., \& de Groot, I. J. (2014). Health-related quality of life and its relation to disease severity in boys with Duchenne muscular dystrophy: Satisfied boys, worrying parents-A casecontrol study. Journal of Child Neurology, 29, 1486-1495. doi:10.1177/0883073813506490

Hoza, B. (2007). Peer functioning in children with ADHD. Journal of Pediatric Psychology, 32, 655-663.

Hu, J., Jiang, L., Hong, S., Cheng, L., Kong, M., \& Ye, Y. (2013). Reliability and validity of the Chinese version of the Pediatric Quality of Life InventoryTM (PedsQLTM) 3.0 neuromuscular module in children with Duchenne muscular dystrophy. Health and Quality of Life Outcomes, 11, 47. doi:10.1186/1477-7525-11-47

Hu, L. T., \& Bentler, P. M. (1999). Cutoff criteria for fit indexes in covariance structure analysis: Conventional criteria versus new alternatives. Structural Equation Modeling, $6,1-55$.

Hysing, M., Elgen, I., Gillberg, C., Lie, S. A., \& Lundervold, A. J. (2007). Chronic physical illness and mental health in children. Results from a large-scale population study. Journal of Child Psychology and Psychiatry, 48, 785-792.

Hysing, M., Elgen, I., Gillberg, C., \& Lundervold, A. J. (2009). Emotional and behavioural problems in subgroups of children with chronic illness: Results from a large-scale population study. Child: Care, Health and Development, 35, 527-533.

Klasen, H., Woerner, W., Rothenberger, A., \& Goodman, R. (2003). German version of the Strength and Difficulties Questionnaire (SDQ-German)-Overview and evaluation of initial validation and normative results. Praxis der Kinderpsychologie und Kinderpsychiatrie, 52, 491-502.

Kroenke, K., Spitzer, R. L., Williams, J. B., \& Löwe, B. (2010). The patient health questionnaire somatic, anxiety, and depressive symptom scales: A systematic review. General Hospital Psychiatry, 32, 345-359.

Kroenke, K., Spitzer, R. L., Williams, J. B., Monahan, P. O., \& Löwe, B. (2007). Anxiety disorders in primary care: Prevalence, impairment, comorbidity, and detection. Annals of Internal Medicine, 146, 317-325.

Landfeldt, E., Lindgren, P., Bell, C. F., Guglieri, M., Straub, V., Lochmüller, H., \& Bushby, K. (2016). Health-related quality of life in patients with Duchenne muscular dystrophy: A multinational, cross-sectional study. 
Developmental Medicine and Child Neurology, 58, 508-515. doi:10.1111/dmcn.12938

Landfeldt, E., Mayhew, A., Straub, V., Lochmüller, H., Bushby, K., \& Lindgren, P. (2018). Psychometric analysis of the pediatric quality of life inventory 3.0 neuromuscular module administered to patients with Duchenne muscular dystrophy: A rasch analysis. Muscle and Nerve, 58, 367-373. doi:10.1002/mus.26109

Leibowitz, D., \& Dubowitz, V. (1981). Intellect and behaviour in Duchenne muscular dystrophy. Developmental Medicine and Child Neurology, 23, 577-590.

Liberati, A., Altman, D. G., Tetzlaff, J., Mulrow, C., Gøtzsche, P. C., Ioannidis, J. P. A., ... Moher, D. (2009). The PRISMA statement for reporting systematic reviews and meta-analyses of studies that evaluate health care interventions: Explanation and elaboration. PLoS Medicine, 6, e1000100.

Lim, Y., Velozo, C., \& Bendixen, R. M. (2014). The level of agreement between child self-reports and parent proxyreports of health-related quality of life in boys with Duchenne muscular dystrophy. Quality of Life Research, 23, 1945-1952. doi:10.1007/s11136-014-0642-7

Lue, Y. J., Chen, S. S., \& Lu, Y. M. (2017). Quality of life of patients with Duchenne muscular dystrophy: From adolescence to young men. Disability and Rehabilitation, 39, 1408-1413. doi:10.1080/09638288.2016.1196398

McDonald, C. M., McDonald, D. A., Bagley, A., Sienko Thomas, S., Buckon, C. E., Henricson, E., ... Sussman, M. D. (2010). Relationship between clinical outcome measures and parent proxy reports of health-related quality of life in ambulatory children with Duchenne muscular dystrophy. Journal of Child Neurology, 25, 1130-1144. doi:10.1177/0883073810371509

Melo, M., Lauriano, V., Gentil, V., Eggers, S., Del Bianco, S. S., Gimenez, P. R., ... Zatz, M. (1995). Becker and limbgirdle muscular dystrophies: A psychiatric and intellectual level comparative study. American Journal of Medical Genetics, 60, 33-38. doi:http://dx.doi.org/10.1002/ajmg. 1320600107

Messina, S., Vita, G. L., Sframeli, M., Mondello, S., Mazzone, E., D’Amico, A., ... Mercuri, E. (2016). Healthrelated quality of life and functional changes in DMD: A 12-month longitudinal cohort study. Journal of Neuromuscular Disorders, 26, 189-196.

Mori-Yoshimura, M., Mizuno, Y., Yoshida, S., Minami, N., Yonemoto, N., Takeuchi, F., ... Kimura, E. (2018). Social involvement issues in patients with Becker muscular dystrophy: A questionnaire survey of subjects from a patient registry. Brain Development, 40, 268-277. doi:http://dx. doi.org/10.1016/j.braindev.2017.11.004

Muntoni, F., Torelli, S., \& Ferlini, A. (2003). Dystrophin and mutations: One gene, several proteins, multiple phenotypes. Lancet Neurology, 2, 731-740.

Nereo, N. E., \& Hinton, V. J. (2003). Three Wishes and psychological functioning in boys with Duchenne muscular dystrophy. Journal of Developmental and Behavioral Pediatrics, 24, 96-103. doi:10.1097/00004703-200304000-00004

Orcesi, S., Ariaudo, G., Mercuri, E., Beghi, E., Rezzani, C., \& Balottin, U. (2014). A new self-report quality of life questionnaire for children with neuromuscular disorders: Presentation of the instrument, rationale for its development, and some preliminary results. Journal of Child Neurology, 29, 167-181. doi:10.1177/ 0883073813511859

Otto, C., Steffensen, B. F., Højberg, A.-L., Barkmann, C., Rahbek, J., Ravens-Sieberer, U., ... Kirschner, J. (2017). Predictors of Health-Related Quality of Life in boys with Duchenne muscular dystrophy from six European countries. Journal of Neurology, 264, 709-723. doi:10.1007/ s00415-017-8406-2

Pane, M., Lombardo, M. E., Alfieri, P., D'Amico, A., Bianco, F., Vasco, G., ... Mercuri, E. (2012). Attention deficit hyperactivity disorder and cognitive function in Duchenne muscular dystrophy: phenotype-genotype correlation. Journal of Pediatrics, 161, 705-709.e701.

Pangalila, R. F., van den Bos, G. A., Bartels, B., Bergen, M., Stam, H. J., \& Roebroeck, M. E. (2015a). Prevalence of fatigue, pain, and affective disorders in adults with Duchenne muscular dystrophy and their associations with quality of life. Archives in Physical Medicine and Rehabilitation, 96, 1242-1247. doi:10.1016/ j.apmr.2015.02.012

Pangalila, R., Bos, G., Bartels, B., Bergen, M., Kampelmacher, M., Stam, H., \& Roebroeck, M. (2015b). Quality of life of adult men with Duchenne muscular dystrophy in the Netherlands: implications for care. Journal of Rehabilitation Medicine, 47, 161-166. doi:10.2340/ 16501977-1898

Pine, D. S., Cohen, P., Gurley, D., Brook, J., \& Ma, Y. (1998). The risk for early-adulthood anxiety and depressive disorders in adolescents with anxiety and depressive disorders. Archives in Genetic Psychiatry, 55, 56-64.

Propp, R., McAdam, L., Davis, A. M., Salbach, N. M., Weir, S., \& Encisa, C. (2018). Development and content validation of the Muscular Dystrophy Child Health Index of Life with Disabilities questionnaire for children with Duchenne muscular dystrophy. Developmental Medicine and Child Neurology, 61, 75-81.

Rahbek, J., Werge, B., Madsen, A., Marquardt, J., Steffensen, B. F., \& Jeppesen, J. (2005). Adult life with Duchenne muscular dystrophy: Observations among an emerging and unforeseen patient population. Pediatric Rehabilitation, 8, 17-28.

Reid, D. T., \& Renwick, R. M. (1994). Preliminary validation of a new instrument to measure life satisfaction in adolescents with neuromuscular disorders. International Journal of Rehabilitation Research, 17, 184-188.

Reid, D. T., \& Renwick, R. M. (2001). Relating familial stress to the psychosocial adjustment of adolescents with Duchenne muscular dystrophy. International Journal of Rehabilitation Research, 24, 83-93.

Ricotti, V., Mandy, W. P. L., Scoto, M., Pane, M., Deconinck, N., Messina, S., ... Muntoni, F. (2016). Neurodevelopmental, emotional, and behavioural problems in Duchenne muscular dystrophy in relation to underlying dystrophin gene mutations. Developmental Medicine and Child Neurology, 58, 77-84.

Smedje, H., Broman, J. E., Hetta, J., \& Von Knorring, A. L. (1999). Psychometric properties of a Swedish version of the "Strengths and Difficulties Questionnaire." European Child \& Adolescent Psychiatry, 8, 63-70. 
Smeets, S. M., Ponds, R. W., Verhey, F. R., \& van Heugten, C. M. (2012). Psychometric properties and feasibility of instruments used to assess awareness of deficits after acquired brain injury: A systematic review. Journal of Head Trauma Rehabilitation, 27, 433-442.

Snow, W. M., Anderson, J. E., \& Jakobson, L. S. (2013). Neuropsychological and neurobehavioral functioning in Duchenne muscular dystrophy: A review. Neuroscience and Biobehavioral Reviews, 37, 743-752.

Solden, J., Guildea, Z. E. S., Antao, V., Street, E., \& Sibert, J. R. (1999). Behavioural and emotional problems in boys with Duchenne's muscular dystrophy: Parental confidence and perception. Child: Care, Health and Development, 5, 331-338.

Spitzer, R. L., Kroenke, K., Williams, J. B., \& Löwe, B. (2006). A brief measure for assessing generalized anxiety disorder: The GAD-7. Archives of Internal Medicine, 166, 1092-1097.

Steele, M., Taylor, E., Young, C., McGrath, P., Lyttle, B. D., \& Davidson, B. (2008). Mental health of children and adolescents with Duchenne muscular dystrophy. Developmental Medicine and Child Neurology, 50, 638-639. doi:10.1111/j.1469-8749.2008.03024.x

Terwee, C. B., Bot, S. D. M., de Boer, M. R., van der Windt, D. A. W. M., Knol, D. L., Dekker, J., ... de Vet, H. C. W. (2007). Quality criteria were proposed for measurement properties of health status questionnaires. Journal of Clinical Epidemiology, 60, 34-42.

Thompson, R. J., Zeman, J. L., Fanurik, D., \& SirotkinRoses, M. (1992). The role of parent stress and coping and family functioning in parent and child adjustment to Duchenne muscular dystrophy. Journal of Clinical Psychology, 48, 11-19. doi:10.1002/10974679(199201)48: $1<11:: \quad$ AIDJCLP2270480103>3.0.CO; 2-4

Uzark, K., King, E., Cripe, L., Spicer, R., Sage, J., Kinnett, K., .. V Varni, J. W. (2012). Health-related quality of life in children and adolescents with Duchenne muscular dystrophy. Pediatrics, 130, e1559-e1566. doi:10.1542/ peds.2012-0858

Visser-Meily, J. A., Post, M. W., Riphagen, I. I., \& Lindeman, E. (2004). Measures used to assess burden among caregivers of stroke patients: A review. Clinical Rehabilitation, 18, 601-623.

Wei, Y., Speechley, K. N., Zou, G., \& Campbell, C. (2015). Factors associated with health-related quality of life in children with Duchenne muscular dystrophy. Journal of Child Neurology, 31, 879-886.

Wei, Y., Speechley, K. N., Zou, G., \& Campbell, C. (2017). The relationship between quality of life and health-related quality of life in young males with Duchenne muscular dystrophy. Developmental Medicine and Child Neurology, 59, 1152-1157. doi:10.1111/dmcn.13574

Wilson, S., Washington, L. A., Engel, J. M., Ciol, M. A., \& Jensen, M. P. (2006). Perceived social support, psychological adjustment, and functional ability in youths with physical disabilities. Rehabilitation Psychology, 51, 322-330.

Whitcomb, S. A. \& Merrell, K. W. (2013). Behavioral, social, and emotional assessment of children and adolescents (4th ed.). New York, NY, US: Routledge/Taylor \& Francis Group.

Woodward, L. J., \& Fergusson, D. M. (2001). Life course outcomes of young people with anxiety disorders in adolescence. Journal of American Academic Child and Adolescent Psychiatry, 40, 1086-1093.

Young, H. K., Barton, B. A., Waisbren, S., Portales Dale, L., Ryan, M. M., Webster, R. I., \& North, K. N. (2008). Cognitive and psychological profile of males with Becker muscular dystrophy. Journal of Child Neurology, 23, 155-162. doi:10.1177/0883073807307975

Zamani, G., Heidari, M., Azizi Malamiri, R., Ashrafi, M. R., Mohammadi, M., Shervin Badv, R., ... Fathi, M. R. (2016). The quality of life in boys with Duchenne muscular dystrophy. Journal of Neuromuscular Disorders, 26, 423-427. doi:10.1016/j.nmd.2016.05.004 